\title{
A EDUCAÇÃO AMBIENTAL NA PERSPECTIVA DOS ESTUDANTES DO CURSO DE PÓS GRADUAÇÃO DO IFES, CAMPUS IBATIBA
}

\author{
Arnaldo Henrique de Oliveira Carvalho ${ }^{1}$ \\ Gabriela Passalini Xavier ${ }^{2}$ \\ Vânia Ágda de Oliveira Carvalho ${ }^{3}$
}

Resumo: Este artigo aborda a percepção que os estudantes do curso de PósGraduação do Instituto Federal do Espírito Santo (IFES), campus Ibatiba, tem sobre a Educação Ambiental (EA). É uma pesquisa aplicada, descritiva, de campo e quantitativa. As questões foram construídas numa escala de Likert e analisadas estatisticamente. Os resultados demonstram, na perspectiva dos alunos, que a EA se constitui num instrumento capaz de promover mudanças, desde que seja trabalhada num viés crítico. Independente de ser uma disciplina específica deve ser trabalhada interdisciplinarmente, não sendo delegada somente à área de ciências da natureza promover ações educativas ambientais. A partir dessa perspectiva foi possível modificar a matriz curricular do curso para ofertar nova turma.

Palavras-chave: Percepção Ambiental; Meio Ambiente; Educação.

Abstract: This article addresses the perception that students of the Postgraduate course at Instituto Federal do Espírito Santo (IFES), campus Ibatiba (ES, Brazil), have about Environmental Education (EE). It is an applied, descriptive, field and quantitative research. The questions were built on a Likert scale and statistically analyzed. The results demonstrate, from the students' perspective, that EE constitutes an instrument capable of promoting changes, if it is worked with a critical bias. Regardless of being a specific discipline, it must be worked interdisciplinary, not being delegated to only the area of natural sciences to promote environmental educational actions. From this perspective, it was possible to modify the course's curriculum to offer a new class.

Keywords: Environmental Perception; Environment; Education.

\footnotetext{
${ }^{1}$ Instituto Federal do Espírito Santo - campus Ibatiba E-mail:. acarvalho@ifes.edu.br Link para o Lattes: http://lattes.cnpq.br/7520766983744062

2 Instituto Federal do Espírito Santo - campus Ibatiba E-mail: gp.passalini@hotmail.com. Link para o Lattes: http://lattes.cnpq.br/9697518167768891

${ }^{3}$ Centro Universitário FAMINAS - Muriaé-MG. E-mail: vaniaagdaocarvalho@gmail.com. Link para o Lattes: http://lattes.cnpq.br/0769658610006569
} 


\section{Introdução}

Frente à eminente crise socioambiental, torna-se fundamental a ressignificação da ação educativa ambiental de forma a promover uma mudança na realidade que se construiu entre homem e meio ambiente (GUIMARÃES, 2004). Essa crise não é simplesmente uma crise de esgotamento dos recursos naturais, mas, como afirma Silva (2013), é uma crise civilizatória de esgotamento de um padrão de racionalidade, sendo, portanto, uma crise de conhecimento.

Os primeiros pressupostos teóricos com função norteadora referentes à Educação Ambiental datam da década de 70 , quando ocorreram os primeiros eventos, nacional e internacional, que reuniram os principais interessados e envolvidos com sua consolidação e enraizamento na sociedade. O surgimento dessa preocupação originou-se em virtude de a humanidade ter percebido um aumento dos impactos ambientais decorrentes dos efeitos prejudiciais promovidos pelas atividades modificadoras do meio, promovendo assim, uma diminuição dos recursos naturais pelo seu uso indiscriminado (FONSECA; BERNARDES, 2015), oportunizando que as práticas educativas ambientais adquirissem uma importância, maior ainda nos dias atuais.

O vocábulo Educação Ambiental, nome que se convencionou dar às práticas educativas relacionadas à questão ambiental, é composto por um substantivo que confere sua essência, definindo os próprios fazeres pedagógicos necessários a esta prática e, por um adjetivo que anuncia 0 contexto dessa prática (LOUREIRO, 2003; LAYRARGUES, 2004). No entanto, o adjetivo ambiental poderia ser dispensado, pois na perspectiva de Pelizzoli (2003) toda educação é ambiental porque não é possível uma educação fora do ambiente.

Implementar práticas educativas, de Educação Ambiental ou simplesmente Educação, obedecem a um processo civilizatório de mudanças desde sua criação (FONSECA; MENDES, 2013), pois todo ato educacional comporta duas possibilidades, uma enquanto reprodutor de um conjunto de valores e outra enquanto ferramenta capaz de produzir mudanças (SOUSA e SANT'ANA, 2018). Assim, entende-se a Educação Ambiental como uma educação política, consistindo em uma proposta emancipatória que busca a superação ou a negação de paradigmas existentes na sociedade globalizada, por constituir-se num contraponto ao modelo hegemônico de desenvolvimento (ALBANI; COUSIN; IBAÑEZ, 2019).

No Brasil, a partir da Política Nacional de Educação Ambiental - PNEA, instituída pela Lei n. 9 9.795/1999, definiram-se vários pontos importantes para a implementação de ações educativas, entre eles a definição que a Educação Ambiental é um componente essencial e permanente da educação nacional, devendo estar presente em todos os níveis e modalidades de ensino, de forma articulada, em seu caráter formal e não formal (BRASIL, 1999). Ou seja, no currículo das escolas e nas comunidades para a coletividade. Caracterizar, assim, a forma como se percebe o ambiente onde se está posto, estabelecendo ao mesmo tempo a ideia de pertencimento, por meio da percepção ambiental, é 
imprescindível para a compreensão das inter-relações entre homem e natureza (FERNANDES et al., 2004).

Os cursos de nível superior no Brasil, entre esses os de pós-graduação, apresentam limitações devido a sua organização curricular, que busca 0 aprofundamento de temas cada vez mais específicos, gerando, com isso, uma fragmentação do ensino, dificultando a compreensão sistemática da problemática ambiental (BALBACHEVSKY, 2005). Soma-se a esta problemática o fato de que a Educação Ambiental não se processa como componente curricular, necessitando de uma integração entre docente, discente, comunidade e questões ambientais, desencadeando pela abordagem inter, multi e transdisciplinar, uma compreensão complexa da sociedade (TRISTÃO, 2004). Dessa forma, estudos de percepção ambiental se mostram importantes para compreender as expectativas, julgamentos e condutas que determinam a relação homem e natureza (FERNANDES et al., 2004).

Dificuldades ainda são notadas no que se refere à delimitação da concepção da Educação Ambiental que cada indivíduo apresenta, esta que só pode ser conhecida à medida que se reflete sobre a problematização de temas socioambientais (CARVALHO et al., 2016). Nesse sentido, para a eficácia das atividades educativas, é importante que o ser humano reflita sobre sua interação com a natureza porque o colapso atual tem levado o mundo à pobreza e à má eficiência dos recursos naturais (ALENCAR e BARBOSA, 2018). Assim, contextualizar a relação do ser humano com a natureza, revela a forma como cada indivíduo se enxerga pertencente a ela (AGOSTINI et al., 2013).

Nesse sentido, objetivou-se analisar o nível de compreensão dos estudantes do curso de Pós-Graduação Lato sensu em Educação Ambiental e Sustentabilidade do Instituto Federal do Espírito Santo - campus lbatiba, sobre Educação Ambiental.

\section{Procedimento metodológico}

A pesquisa foi realizada com os estudantes da segunda turma do curso de Pós-Graduação Lato sensu em Educação Ambiental e Sustentabilidade do Instituto Federal do Espírito Santo - IFES, campus Ibatiba, turma de 2018. A pesquisa se classifica como aplicada, descritiva, de campo e quantitativa.

A análise foi realizada a partir da aplicação de um questionário para identificar: o perfil dos estudantes; a percepção dos estudantes às distintas abordagens de Educação Ambiental; a importância da temática na formação profissional e na vida em sociedade; a percepção quanto à aplicação de práticas sustentáveis nos diversos processos educativos. O projeto foi submetido ao Comitê de Ética em Pesquisa do Instituto Federal do Espírito Santo, o qual aprovou e autorizou sua realização por meio do parecer 3.140 .550 , expedido no dia 11 de fevereiro de 2019.

O questionário foi aplicado durante a primeira aula da disciplina de 
garantindo o sigilo, bem como 0 anonimato e 0 respeito à privacidade. Anteriormente à aplicação do questionário os estudantes foram orientados, esclareceu-se o objetivo da pesquisa e que teriam resguardado o direito a não participação caso considerassem a abordagem inadequada. Após sanada as dúvidas, preencheram o Termo de Consentimento Livre e Esclarecido.

Os estudantes que não desejassem responder o questionário seriam convidados a assistir mostras audiovisuais sobre a Educação Ambiental do Circuito Tela Verde, promovidas pelo Ministério do Meio Ambiente, em outra sala, com a duração aproximada da aplicação do questionário.

As questões do questionário foram estruturadas numa escala Likert, que permitiu avaliar as perspectivas dos estudantes quanto a suas atitudes e conhecer o grau de conformidade quanto à Educação Ambiental. A escala de Likert é uma escala de mensuração (ou medição), definida com atribuição de símbolo (numérico) à propriedade dos objetos que se deseja medir, direcionados a quantificar ou classificar as características determinadas (SILVA JÚNIOR; COSTA, 2014). Assim, os indicadores foram afirmações sobre o construto (pergunta) e teve uma escala de verificação com níveis de concordância de 1 a 9, onde o 1 indica menor nível de concordância e o 9 , maior nível de concordância.

A análise dos dados foi realizada com procedimento estatístico descritivo. Inicialmente foi realizada a avaliação de confiabilidade do questionário por meio do uso do coeficiente Alfa de Cronbach (MATTHIENSEN, 2011), analisando divergências e similaridades entre as métricas da escala de Likert. Para uma melhor análise dos resultados, foi realizada uma abordagem quantitativa para estabelecer o Ranking Médio (RM) (OLIVEIRA, 2005). Para o questionário foi utilizada escala Likert de 9 pontos para mensurar o grau de concordância dos sujeitos que responderam os questionários. Realizou-se a verificação quanto à concordância ou discordância das questões avaliadas, através da obtenção do RM da pontuação atribuída às respostas, relacionado à frequência das respostas dos respondentes que fizeram tal atribuição, onde os valores menores que 5 são considerados como discordantes e, maiores que 5 , como concordantes, considerando uma escala de 9 pontos. Todos os procedimentos foram realizados no software Action Stat versão 3.3.2 (2018).

\section{Resultados e discussão}

Fizeram parte da pesquisa todos os 33 estudantes matriculados na turma de 2018. Dentre os estudantes, observa-se um maior número de alunos do gênero feminino, $15,2 \%$ superior em relação aos alunos do gênero masculino (Tabela 1). A predominância de mulheres foi apontada no Censo da Educação Superior revelando uma expressiva presença feminina nos cursos de nível superior no Brasil (INEP, 2019), entre esses, os cursos de pós-graduação. 
Tabela 1: Estudante matriculados por gênero, por faixa etária e por estado de origem

\begin{tabular}{cccccc}
\hline Gênero & Faixa etária & ES & MG & Total geral & $\%$ \\
\hline \multirow{3}{*}{ Feminino } & Até 29 anos & 9 & 3 & 12 & \\
& de 30 a 35 & 4 & & 4 & 57,6 \\
& de 36 a 40 & 1 & 1 & 2 & \\
& de 41 a 50 & 1 & & 1 & \\
\hline \multirow{3}{*}{ Masculino } & Até 29 anos & 5 & 3 & 8 & \\
& de 30 a 35 & 4 & & 4 & \\
& de 36 a 40 & 1 & & 1 & \\
& de 41 a 50 & 1 & & 1 & $\mathbf{1 0}$ \\
\hline Total geral & & $\mathbf{1 1}$ & $\mathbf{3}$ & $\mathbf{1 4}$ & \\
\hline
\end{tabular}

Fonte: Elaborado pelos autores.

Quanto à idade dos estudantes matriculados no curso, $84,8 \%$ apresentam idade até 35 anos, ou seja, alunos jovens, e a maioria residente no estado do Espírito Santo (78,8\%) (Tabela 1). Desde 2016 nota-se um aumento do número de alunos que frequentam cursos de especialização de nível superior no Brasil e cerca de 45\% têm idade entre 25 e 34 anos (SEMESP, 2019). É importante saber o perfil dos estudantes ou da comunidade que se pretende desenvolver ações ambientais pois, à medida que se conhece esse público, a implementação de estratégias para aprendizagem é favorecida, além de garantir maior eficiência no processo educativo (GOMES; MOTA; LEONARDO, 2014).

Por se tratar de um curso multidisciplinar, constata-se uma grande diversificação quanto à área de conhecimento dos estudantes. Dentre os alunos matriculados há uma predominância de estudantes da área de engenharias (11) seguido por estudantes oriundos das ciências biológicas (6) (Tabela 2).

Dos estudantes matriculados uma parcela majoritária é egressa de instituição privada de ensino $(69,7 \%)$ (Tabela 2$)$. Muito embora o curso seja ofertado por uma instituição pública, dos alunos que frequentam cursos de pósgraduação no Brasil, $88 \%$ estão matriculados em instituições privadas, apesar de, nos últimos anos, ter havido um crescimento na oferta de cursos de pósgraduação na rede pública de ensino em cerca de 41\% (SEMESP, 2019).

Com os dados do questionário calculou-se o somatório das variâncias dos itens e a soma das variâncias dos respondentes $\left(k=33 ; \quad \sum S^{2}=15,66\right.$; $S^{2}{ }_{t}=49,32$ ) (Tabela 3), parâmetros utilizados para o cálculo do Alfa de Cronbach. 
Tabela 2: Estudantes matriculados por gênero, por área do conhecimento e por categoria administrativa.

\begin{tabular}{|c|c|c|c|c|c|}
\hline Gênero & Áreas do conhecimento & Privada & Pública & Total geral & $\%$ \\
\hline \multirow{7}{*}{ Feminino } & Ciências Agrárias & & 1 & 1 & \multirow{6}{*}{57,6} \\
\hline & Ciências Biológicas & 5 & & 5 & \\
\hline & Ciências Humanas & 3 & 1 & 4 & \\
\hline & Ciências Sociais Aplicadas & 2 & & 2 & \\
\hline & Engenharias & 5 & 1 & 6 & \\
\hline & Exatas e da Terra & & 1 & 1 & \\
\hline & & 15 & 4 & 19 & \\
\hline \multirow{8}{*}{ Masculino } & Ciências Agrárias & & 2 & 2 & \multirow{7}{*}{42,4} \\
\hline & Ciências Biológicas & 1 & & 1 & \\
\hline & Ciências Humanas & 1 & & 1 & \\
\hline & Ciências Saúde & 1 & & 1 & \\
\hline & Ciências Sociais Aplicadas & 1 & & 1 & \\
\hline & Engenharias & 3 & 2 & 5 & \\
\hline & Exatas e da Terra & 1 & 2 & 3 & \\
\hline & & 8 & 6 & 14 & \\
\hline Total geral & & 23 & 10 & 33 & 100 \\
\hline
\end{tabular}

Fonte: Elaborado pelos autores.

Tabela 3: Respostas dos avaliadores aos itens do questionário do Teste tipo Likert.

\begin{tabular}{|c|c|c|c|c|c|c|c|c|}
\hline \multicolumn{9}{|c|}{ Item } \\
\hline Avaliadores & 1 & 2 & 3 & 4 & 9 & 10 & Total & variância \\
\hline 1 & 9 & 8 & 9 & 9 & 9 & 9 & 53 & 189,20 \\
\hline 2 & 9 & 6 & 9 & 9 & 9 & 8 & 50 & 211,90 \\
\hline 3 & & 9 & 3 & 2 & 6 & 6 & 26 & 439,78 \\
\hline 4 & 9 & 9 & 5 & 5 & 8 & 9 & 45 & 252,59 \\
\hline 5 & 9 & 9 & 7 & 9 & 9 & 9 & 52 & 196,62 \\
\hline 6 & 7 & 8 & 4 & 7 & 9 & 8 & 43 & 269,86 \\
\hline 7 & 9 & 9 & 9 & 9 & 9 & 9 & 54 & 181,92 \\
\hline 8 & 9 & 9 & 9 & 9 & 7 & 9 & 52 & 196,62 \\
\hline 9 & 9 & 6 & 9 & 8 & 9 & 9 & 50 & 211,90 \\
\hline 10 & 9 & 6 & 4 & 6 & 8 & 7 & 40 & 296,85 \\
\hline 11 & 5 & 7 & 5 & 3 & 6 & 5 & 31 & 385,52 \\
\hline 12 & 9 & 9 & 7 & 6 & 9 & 9 & 49 & 219,75 \\
\hline 13 & 9 & 9 & 9 & 9 & 9 & 9 & 54 & 181,92 \\
\hline 14 & 9 & 9 & 9 & 9 & 9 & 8 & 53 & 189,20 \\
\hline 15 & 9 & 9 & 9 & 8 & 9 & 9 & 53 & 189,20 \\
\hline 16 & 9 & 6 & 8 & 6 & 9 & 9 & 47 & 235,88 \\
\hline 17 & 9 & 9 & 9 & 9 & 9 & 9 & 54 & 181,92 \\
\hline 18 & 9 & 9 & 7 & 9 & 9 & 9 & 52 & 196,62 \\
\hline 19 & 9 & 9 & 9 & 9 & 9 & 8 & 53 & 189,20 \\
\hline 20 & 9 & 8 & 1 & 9 & 8 & 9 & 44 & 261,15 \\
\hline 21 & 9 & 7 & 2 & 9 & 9 & 7 & 43 & 269,86 \\
\hline 22 & 9 & 9 & 9 & 9 & 9 & 8 & 53 & 189,20 \\
\hline 23 & 8 & 8 & 2 & 3 & 8 & 7 & 36 & 334,83 \\
\hline 24 & 7 & 6 & 7 & 8 & 8 & 8 & 44 & 261,15 \\
\hline 25 & 9 & 9 & 7 & 9 & 7 & 7 & 48 & 227,74 \\
\hline 26 & 7 & 7 & 3 & 3 & 9 & 8 & 37 & 325,12 \\
\hline 27 & 9 & 9 & 9 & 8 & 8 & 9 & 52 & 196,62 \\
\hline & & & & & & & & Continua \\
\hline
\end{tabular}

Revbea, São Paulo, V.16, № 5: 156-174, 2021.

revista brasileira 


\begin{tabular}{ccccccccc}
...continuação. & \multicolumn{10}{c}{ Item } \\
\hline Avaliadores & $\mathbf{1}$ & $\mathbf{2}$ & $\mathbf{3}$ & $\mathbf{4}$ & $\mathbf{9}$ & $\mathbf{1 0}$ & Total & variância \\
\hline 28 & 9 & 9 & 9 & 9 & 9 & 9 & 54 & 181,92 \\
29 & 9 & 9 & 3 & 8 & 9 & 8 & 46 & 244,16 \\
30 & 9 & 9 & 9 & 9 & 8 & 7 & 51 & 204,19 \\
31 & 9 & 7 & 9 & 6 & 7 & 7 & 45 & 252,59 \\
32 & 9 & 9 & 7 & 9 & 8 & 8 & 50 & 211,90 \\
33 & 9 & 9 & 9 & 9 & 8 & 9 & 53 & 189,20 \\
\hline Total & 277 & 270 & 226 & 249 & 276 & 269 & & \\
Média & 8,65 & 8,18 & 6,84 & 7,54 & 8,36 & 8,15 & & \\
Variância & 0,81 & 1,34 & 7,00 & 4,63 & 0,80 & 1,07 & 15,66 & \\
\hline
\end{tabular}

Fonte: Elaborado pelos autores.

O Alfa de Cronbach considerando as 10 questões previstas inicialmente no questionário para analisar a compreensão sobre o entendimento da Educação Ambiental não foi confiável $(0,71)$, visto encontrar-se abaixo da faixa de valores aceitável $(0,80$ e 0,90$)$ (STREINER, 2003). Assim, para ajustar o coeficiente, quatro (04) itens que apresentaram variância alta foram retirados, permitindo encontrar um Alfa de Cronbach dentro de uma faixa aceitável $(0,82)$. Dessa forma, a confiabilidade do questionário foi de $82 \%$, demonstrando uma homogeneidade entre os itens restantes, medindo, consistentemente, a escala, segundo a característica para a qual foi criada, apresentando uma consistência interna com boa confiabilidade.

Para analisarmos as questões, calculamos também o Ranking Médio individual (RM) de cada questão e depois a média aritmética entre os RM de cada categoria que foram estabelecidas (Tabela 4). Quanto mais próximo de 9 o RM estiver, maior será o nível de satisfação dos estudantes naquela questão e quanto mais próximo de 1 menor será a satisfação. A média aritmética entre os RM de foi 7,91 (Tabela 4).

Tabela 4: Distribuição de frequência do número de respondentes referente a cada questão

\begin{tabular}{|c|c|c|c|c|c|c|c|c|c|c|}
\hline \multirow{2}{*}{ Questão } & \multicolumn{9}{|c|}{ Item } & \multirow{2}{*}{ RM } \\
\hline & 1 & 2 & 3 & 4 & 5 & 6 & 7 & 8 & 9 & \\
\hline 1 & & & & & 1 & & 3 & 1 & 28 & 8,70 \\
\hline 2 & & & & & & 5 & 4 & 4 & 21 & 7,70 \\
\hline 3 & 1 & 2 & 2 & 2 & 2 & & 6 & 1 & 17 & 7,03 \\
\hline 4 & & 1 & 3 & & 1 & 4 & 1 & 5 & 18 & 7,54 \\
\hline 9 & & & & & & 2 & 3 & 9 & 19 & 8,36 \\
\hline 10 & & & & & 1 & 1 & 6 & 9 & 16 & 8,15 \\
\hline RM médio & & & & & & & & & & 7,91 \\
\hline
\end{tabular}

Fonte: Elaborado pelos autores.

Considerando o termo Educação Ambiental, 97\% dos estudantes 
1), sendo o instrumento inicial para ações de sensibilização ao enfrentamento dos problemas socioambientais. Essa percepção é confirmada pelo Ranking Médio (RM) individual de 8,70 (Tabela 4), superior à média dos Ranking Médios $(7,91)$, evidenciando um bom nível de satisfação quanto à compreensão do termo Educação Ambiental. Percebe-se na sociedade um consenso de que, a gravidade dos problemas ambientais é decorrente de um modelo de desenvolvimento econômico que promove muitos impactos negativos e que a Educação Ambiental é, como afirma Guimarães (2016), uma importante ação para a superação destes problemas.

Corroborando com o entendimento dos estudantes, Rosa e Silva (2002), afirmam que a Educação Ambiental se mostra como um caminho viável para o enfrentamento das questões ambientais, possibilitando, por intermédio do processo educativo, atingir um nível de consciência por meio de uma sensibilização coletiva, produzindo em cada indivíduo um ponto de vista crítico e reflexivo, que promova, na concepção de Medeiros et al. (2011), uma mudança comportamental. Dessa maneira, Massi (2016) apresenta que o processo educativo deva ser um ato político no sentido mais amplo, como prática social cuja tendência é a construção de sujeitos políticos, aptos para atuarem criticamente na sociedade.

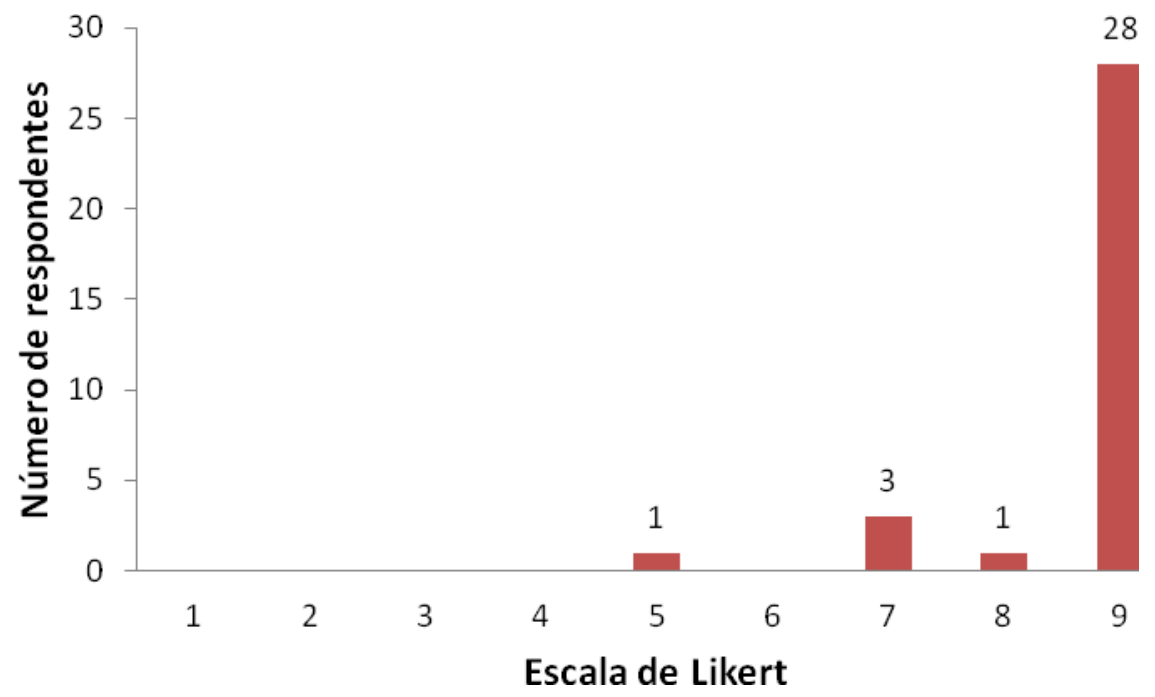

Figura 1: Concordância quanto à Educação Ambiental ser uma ferramenta que permite 0 entendimento das questões ambientais. Fonte: Elaborado pelos autores.

Questionados sobre a efetividade do processo educativo com a realização de ações por meio de projetos nas escolas, nas comunidades e nas unidades de conservação com intervenção das disciplinas da área de ciências naturais, todos concordaram que tais ações são efetivas no processo educativo ambiental (Figura 2). Apesar da unanimidade quanto à concordância da efetividade dessas ações no processo educativo, o grau de satisfação, revelado pelo RM de 7,70 ficou abaixo da média e afastado da escala máxima (Tabela 4). 


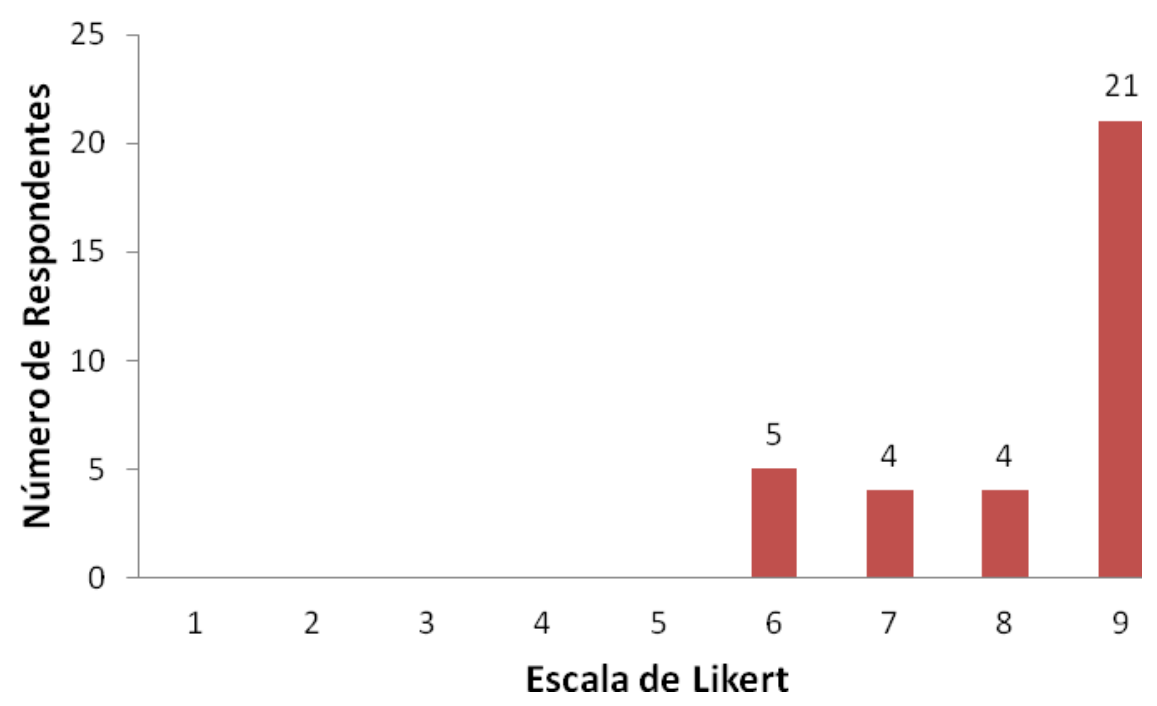

Figura 2: Concordância quanto à efetividade do processo educativo com intervenção das disciplinas da área de ciências naturais. Fonte: Elaborado pelos autores.

Esse afastamento pode ser explicado uma vez que a Educação Ambiental é tratada de maneira conservadora e limitada nas instituições de ensino, sendo praticada em ações pontuais (SOUSA FILHO et al., 2015), por algumas disciplinas, especialmente aquelas ligadas às ciências da natureza, pois, para Eduardo et al. (2018), as disciplinas ligadas a essa área são eleitas como as que obrigatoriamente se responsabilizam por tal tarefa, a exemplo das disciplinas de ciências e biologia. Por outro lado, Lander (2005) ressalta que as ciências sociais, que estudam os fatores humanos, não devem ser menosprezadas, pois esta área estuda os fenômenos da sociedade como os conflitos sociais, a dinâmica das sociedades, analisando os processos históricos de transformação das organizações sociais permitindo uma melhor compreensão da relação que existe entre a sociedade e a natureza.

Devido seu caráter inter, multi e transdisciplinar, a Educação Ambiental contribui, segundo Fonseca e Bernardes (2015), para o estudo em diversas áreas e, portanto, tem recebido cada vez mais importância na sociedade, uma vez que perpassa por todas as áreas do conhecimento e, assim, amplia gradativamente, sua presença no cenário acadêmico brasileiro (SILVA, 2013). Dessa forma, o processo educativo voltado para as questões ambientais contemporâneas, pode se concretizar a partir do ensino das disciplinas de ciências naturais em diferentes espaços, não devendo ficar, contudo, restrita à dimensão natural, mas também seja compreendida tanto na dimensão científica como humana e social (CAVALCANTI NETO; AMARAL, 2011). Nesse sentido, Almeida (2007) afirma que a Educação Ambiental contribuirá para que os indivíduos adquiram os conhecimentos e desenvolvam as competências necessárias para o exercício de uma cidadania responsável. 
Todavia, é papel das instituições de ensino assumirem seu papel transformador na consecução da Educação Ambiental, criar espaços para o desenvolvimento da reflexão crítica sobre o atual contexto socioambiental (GELATI; FAORO, 2017), e assim propiciar o questionamento mais profundo a cada um dos seus participantes, visto que a complexidade ambiental insere as instituições de ensino no debate de possibilidades dentro da racionalidade estabelecida (CARNIATTO; STEDING, 2015). Reconhecendo a importância da inserção da temática ambiental e a relevância das instituições de ensino para a formação em Educação Ambiental, Ribeiro e Malvestio (2021), apontam dificuldades, visto que essa inserção ainda não se efetivou em diversos cursos, e aqueles que já a inseriram, enfrentam dificuldades, especialmente para a prática da interdisciplinaridade e prática a partir de uma abordagem crítica.

Do confronto dos dados colhidos com o levantamento da literatura, constata-se, indubitavelmente, a percepção de que a Educação Ambiental é um instrumento capaz de alterar comportamentos individuais e, em escala ampliada, de todo uma coletividade, mesmo que a médio e longo prazo, haja vista possibilitar aos indivíduos a compreensão sobre as questões ambientais cotidianas. Contudo, a maioria dos estudantes que responderam à pesquisa, ainda creem que a temática da Educação Ambiental se vê adstrita à área das ciências naturais, demonstrando, assim, dificuldade na compreensão do objeto da Educação Ambiental como plural, na conjectura da união entre os princípios indissociáveis natureza, economia e sociedade, não encontrando, dessa forma, respaldo na literatura que, ao contrário, afirma e destaca a suma importância da dimensão científica das humanísticas, em geral, tendo em vista a complexidade dos objetos inseridos na própria compreensão de meio, abarcando, dessa maneira, a temática socioambiental, retirando-se da visão ainda conservacionista e pragmática que a maioria se encontra.

Noutro vértice, porém não incomunicável com os demais apontamentos, no que tange à efetividade do processo educativo com a realização de ações por meio de projetos com intervenção das disciplinas da área de ciências naturais, todos concordaram que tais ações são efetivas no processo educativo ambiental, o que, de certa forma, coaduna com o liame crédulo dos estudantes que responderam à pesquisa, referente à primazia das áreas das ciência naturais sobre as demais, enaltecendo ainda mais a relevância em se apresentar e discutir, de forma mais aprofundada, a importância do caráter inter, multi e transdisciplinar da Educação Ambiental, conforme elucida a literatura.

Desde o seu surgimento na década de 1970 (DIAS, 2004), o entendimento sobre quem deveria fazer Educação Ambiental tem-se ampliado visto que essa tarefa era destinada a alguns professores, principalmente das disciplinas de ciências, biologia e geografia. Essa ideia ficou tão enraizada que ainda atualmente, cerca de 50 anos após seu surgimento, a maioria dos estudantes (42,7\%) ainda acreditam que a Educação Ambiental deve ser trabalhada como uma disciplina específica ao longo de todos os níveis de ensino e somente $21,2 \%$ discordam que seja responsabilidade de uma única disciplina tratar dessa temática (Figura 3). O baixo nível de satisfação nesse item é 
revelado pelo menor $\mathrm{RM}(7,03)$ (Tabela 4) demonstrando ser um assunto que precisa ser mais bem debatido.

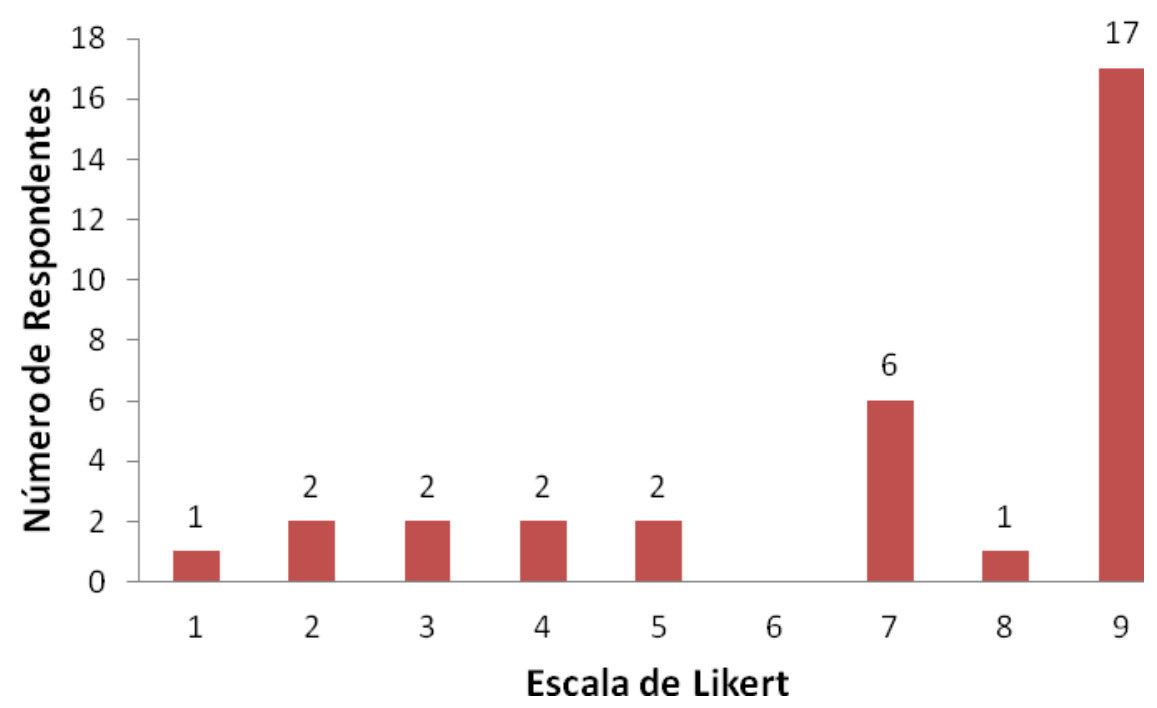

Figura 3: A Educação Ambiental deveria ser trabalhada como uma disciplina específica Fonte: Elaborado pelos autores.

Ademais, em que pese a compreensão da maioria dos estudantes em vislumbrar a necessidade de que a Educação Ambiental deva ser trabalhada como disciplina específica, não corrobora com o viés transversal e holístico destinado ao instrumento de caráter conscientizador, inclusive em vias de normatividade, ou seja, tanto a tratativa legal quanto a literária afirmam a inviabilidade de trabalhar a Educação Ambiental como disciplina curricular própria, visto que a Lei $n$. - 9.795/1999 estabelece que sua abordagem deve ser integrada e contínua, e não deve ser esta implantada como uma nova disciplina, autônoma e independente, no currículo. Apesar da orientação legal quanto ao viés necessário e transversal, a implantação da Educação Ambiental em todos os níveis de ensino da educação brasileira ainda se encontra distante da efetividade prática (SILVA, 2013).

Destaca-se a importância do caráter inter, multi e transdisciplinar da Educação Ambiental, visto que não ficaria exclusivamente a uma determinada área ou disciplina a responsabilidade de desenvolver ações ambientais, mas sim a todas as áreas e disciplinas em todos os níveis de ensino, de forma integrada, articulada e sistêmica. Além do mais, que fosse abordada de forma transversal ao ensino, à pesquisa e à extensão (ALENCAR; BARBOSA, 2018). Como disse Torres e Maestrelli (2012), um dos desafios atuais do campo da Educação Ambiental no contexto escolar brasileiro, é a dificuldade em implementá-la nos currículos das escolas, devido à carência de processos formativos de professores, ou seja, capacitação, e a escassez de aportes teóricometodológicos viáveis, que possibilitem a apropriação do método e não sua repetição. Fonseca (2016) relata que a Educação Ambiental foi internalizada 
como disciplina, alcançando os alunos que frequentam o ensino básico, por meio da discussão, decisão e encaminhamentos conjuntos, atribuindo responsabilidades, o que possibilita superar o fracionamento do conhecimento.

No que diz respeito às ações educativas, elas são conduzidas seguindose uma determinada vertente ou macrotendência pedagógica da Educação Ambiental, apontadas por Layrargues e Lima (2014) como conservadoras, pragmáticas ou críticas. Nota-se que $84,8 \%$ dos estudantes (Figura 4) concordam que a Educação Ambiental deve ser centrada em ações que buscam a conservação e preservação dos recursos naturais e da biodiversidade, ou seja, uma visão conservacionista ou pragmática, visto que suas atividades são voltadas para o comportamento e de forma individualista, enquanto apenas $12,1 \%$ discordam dessa abordagem, o que conduz para uma vertente crítica, alternativa, capaz de promover ações transformadoras e emancipatórias. A discordância e a insatisfação dos estudantes, com relação a esse item, é demonstrada pelo RM abaixo do média, 7,53 (Tabela 4).

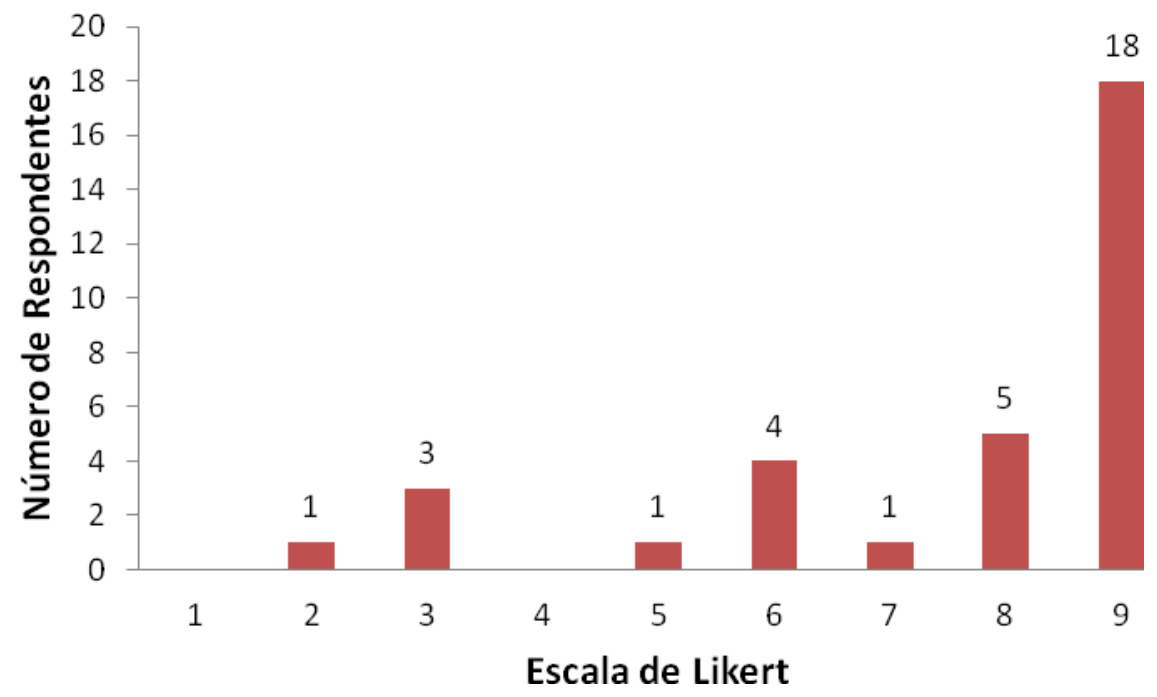

Figura 4: Foco das ações de Educação Ambiental devem ser centradas na conservação e na preservação dos recursos naturais e da biodiversidade. Fonte: Elaborado pelos autores.

Na medida em que não há uma única Educação Ambiental, uma certa e outra errada, o que deve haver é uma tendência de ação, política e intencional, que conduza os indivíduos em um caminho reflexivo, permitindo-os compreender a realidade socioambiental e buscar, a partir desse entendimento, o enfrentamento das questões ambientais e encontrar alternativas viáveis para os problemas vividos, constituindo-se num importante instrumento de transformação social, numa perspectiva sociocrítica, ancorada no paradigma sistêmico, na ética do cuidado e nos princípios da corresponsabilidade, autonomia e solidariedade (SILVA et al., 2012).

Via de regra, ao se planejar ações de Educação Ambiental deve-se considerar seus objetivos fundamentais definidos pela PNEA (BRASIL, 1999), os 
quais fornecem uma delimitação ao tema, detalhando os processos necessários para a realização das ações educativas e mais, que resultados pretende alcançar. Nesse sentido, todos concordaram ser um dos objetivos da Educação Ambiental promover o questionamento às diferentes abordagens cotidianas, objetivando a transformação socioambiental e econômica (Figura 5). O nível de satisfação dos estudantes nesse item foi bom, visto que o RM ficou acima da média $(8,36)$, aproximando do nível máximo de concordância.

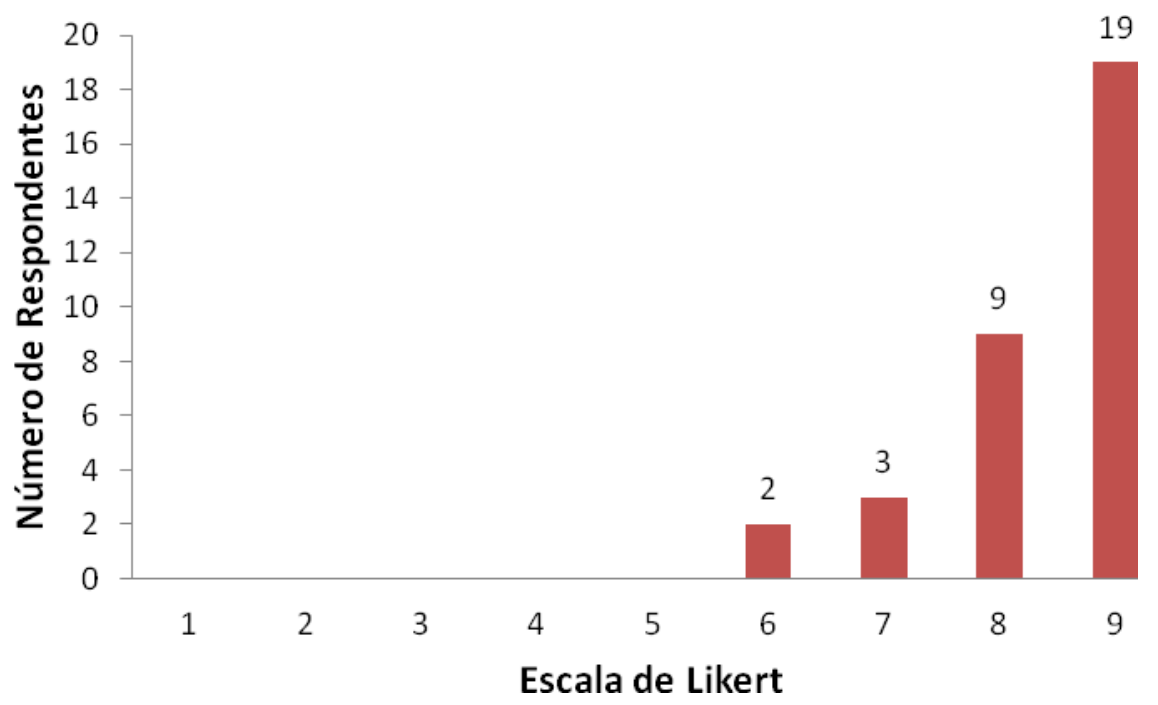

Figura 5: A Educação Ambiental promove o questionamento às diferentes abordagens cotidianas. Fonte: Elaborado pelos autores.

Nos últimos anos a Educação Ambiental ganhou espaço na sociedade mas, no entanto, essa mesma sociedade tem degradado mais o meio ambiente (GUIMARÃES, 2016). Esse paradoxo apresentado pelo autor faz refletir num direcionamento que deve ser dado às ações de Educação Ambiental, ações que conduzam para um debate mais amplo, dentro de um processo crítico, questionador do atual modelo de desenvolvimento dominante, que é injusto e insustentável.

Nesse cenário, $97 \%$ dos estudantes concordam que refletir a crise social por meio de ações educativas pode ser uma importante ferramenta de cidadania, na busca de uma emancipação socioambiental (Figura 6). Satisfação alta, 8,15 (Tabela 4), maior que o RM médio, e próximo da maior pontuação.

Conforme se viu, mesmo compreendendo que a Educação Ambiental tem um potencial para conduzir os indivíduos num processo educativo reflexivo e crítico, pouco dessa tendência crítica é posto em prática, prevalecendo uma tendência conservadora nas ações e práticas educativas. Como disse Albani e Cousin (2015) torna-se cada vez mais evidente a importância da Educação Ambiental no sentido transformador, cuja complexidade requer um trabalho interdisciplinar comprometido, que seja concebida como práxis, que considere 
sua multidimensionalidade, permeando todos os espaços formais e não formais da sociedade (ALBANI; COUSIN; IBAÑEZ, 2019).

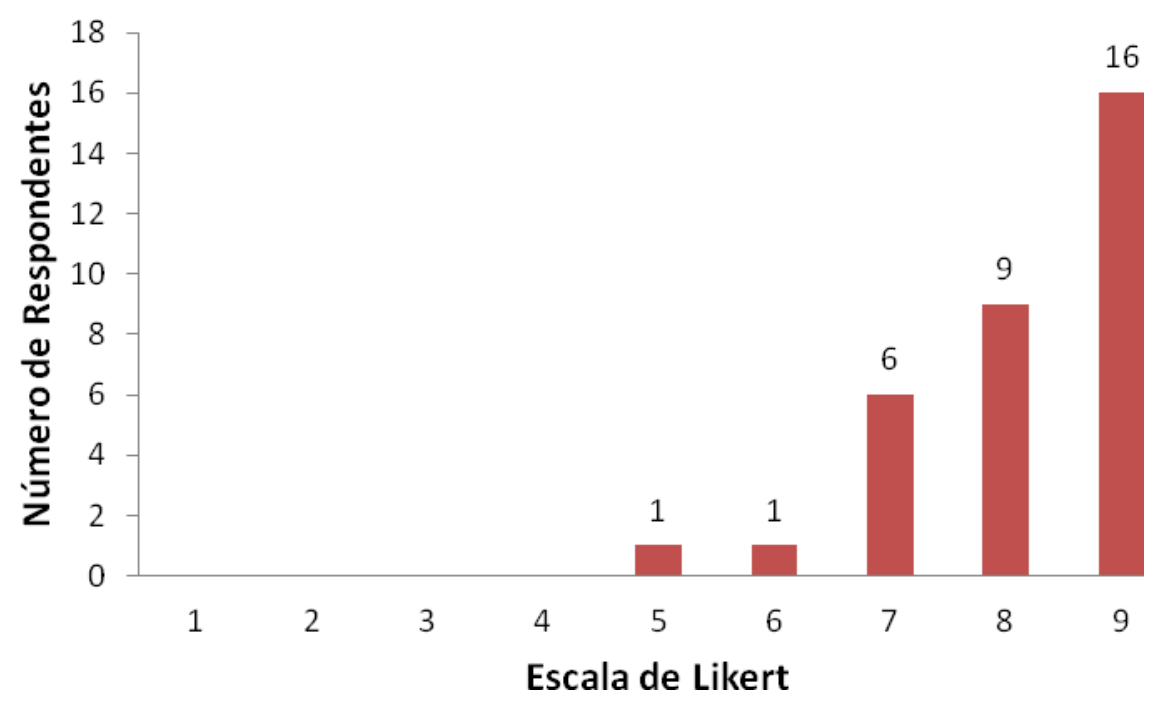

Figura 6: Refletir sobre a crise social por meio da Educação Ambiental pode ser uma ferramenta de cidadania. Fonte: Elaborado pelos autores.

Diante desse contexto, no qual há o reconhecimento da importância e evolução da Educação Ambiental frente às questões ambientais, desacompanhada da redução da degradação ambiental, uma mudança cultural se faz necessária (SORRENTINO; BIOSOLI, 2014). Essa mudança virá com a aproximação entre as instituições de ensino, movimentos sociais e ambientalistas, a educação popular, voltando-se para a formação humana e política, com o propósito de transformar a sociedade (LOUREIRO, 2004; LOUREIRO; LAYRARGUES, 2013). Para tanto, além da PNEA (BRASIL, 1999), dispomos de outros instrumentos que orientam sobre a implementação da Educação Ambiental no Brasil, como o Programa Nacional de Educação Ambiental - ProNEA (BRASIL, 2005), os Parâmetros Curriculares Nacionais PCNs (BRASIL, 1998) e as Diretrizes Curriculares da Educação Ambiental (BRASIL, 2012). Estes documentos orientam a implementação da Educação Ambiental, formal e não formal, sugerindo uma abordagem transversal da temática ambiental como conteúdo de todas as disciplinas do currículo escolar, inclusive a consideram como atividade intencional da prática social, que deve imprimir ao desenvolvimento individual um caráter social (ALBANI; COUSIN, 2015). 


\section{Considerações finais}

A Educação Ambiental promoverá o entendimento das questões ambientais desde que haja intencionalidade em suas práticas que conduzirá ao enfrentamento da problemática ambiental, contanto que seja um ato político.

A partir do ponto de vista dos estudantes dessa segunda turma do curso de pós-graduação do IFES - campus Ibatiba, promoveu-se uma reflexão sobre a estrutura curricular, levando-nos a modificar sua matriz pois, dentre as disciplinas ofertadas para a formação dos estudantes, apenas uma trabalhava efetivamente a Educação Ambiental, apesar das demais estarem inseridas na temática ambiental, abrangendo as áreas de engenharias, matemática, ciências humanas e ciências da natureza. Assim, para a oferta da terceira turma, foram introduzidas duas outras disciplinas, Bases Filosóficas da Educação Ambiental e Didática Aplicada à Educação Ambiental, ampliando a abordagem sobre a Educação Ambiental.

Além disso, realizamos um debate entre os professores sobre a necessidade, independente da disciplina, de trabalhar os conteúdos interdisciplinarmente, esse apontado pela literatura como um dos maiores desafios para a Educação Ambiental. Para tanto, a rotina de planejamento conjunto entre os docentes deve ser implementada, com vistas a alcançar a prática interdisciplinar.

\section{Agradecimentos}

Ao Instituto Federal do Espírito Santo pela bolsa de extensão para a segunda autora referente ao Programa Sala Verde Caparaó. Ao Ministério do Meio Ambiente pelo apoio à Sala Verde Caparaó.

\section{Referências}

AGOSTINI, V. O. et al. Análise da percepção ambiental dos alunos visitantes do museu de ciências naturais do Ceclimar / IB / UFRGS, IMBÉ ( RS ). Revista Brasileira de Educação Ambiental, v. 8, n. 2, p. 93-102, 2013.

ALBANI, I. C.; COUSIN, C. da S. A Educação Ambiental crítica e transformadora no movimento sindical lonara. Rev. Eletrônica Mestr.Educ. Ambient., n. I, p. 53-70, 2015.

ALBANI, I. C.; COUSIN, C. DA S.; IBAÑEZ, M. E. A Educação Ambiental no Brasil e na Espanha: reflexões alicerçadas na perspectiva crítica e transformadora. Rev. Eletrônica Mestr. Educ. Ambient., v. 36, n. 3, p. 212234, 2019.

ALENCAR, L. D. DE; BARBOSA, M. de F. N. Educação Ambiental no Ensino Superior: ditames da Política Nacional de Educação Ambiental. Revista Direito Ambiental e Sociedade, v. 8, n. 2, p. 229-255, 2018. 
ALMEIDA, A. Que papel para as Ciências da Natureza em Educação Ambiental ? Discussão de ideias a partir de resultados de uma investigação. Revista Electrónica de Enseñanza de las Ciencias, v. 6, n. 3, p. 522-537, 2007.

BALBACHEVSKY, E. A pós-graduação no Brasil: novos desafios para uma política bem-sucedida. In: BROCK. C.; SCHWARTZMAN, S. Os desafios da educação no Brasil. Rio de Janeiro: Nova Fronteira, 2005. p. 275-304.

BRASIL. Política Nacional de Educação Ambiental, Lei no 9.795, de 27 de abril de 1999. Brasília, DF, 1999. Disponível em: $<$ http://www.planalto.gov.br/ccivil 03/leis/L9795.htm>. Acesso em 26 de junho de 2020.

BRASIL. Ministério do Meio Ambiente e Ministério da Educação. Programa Nacional de Educação Ambiental. Brasília: MMA e MEC, 3 ed. 2005. 102 p. Disponível em: $<$ https://www.mma.gov.br/estruturas/educamb/ arquivos/pronea3.pdf> Acesso em 26 de junho de 2020.

BRASIL. Parâmetros curriculares nacionais: terceiro e quarto ciclos: apresentação dos temas transversais. Meio Ambiente. Brasília: MEC/ Secretaria de Educação Fundamental, 1998.436 p. Disponível em: $<$ http://portal.mec.gov.br/seb/arquivos/pdf/ttransversais.pdf>. Acesso em 26 de junho de 2020.

BRASIL. Resolução no 2, de 15 de junho de 2012. Estabelece as Diretrizes Curriculares Nacionais para a Educação Ambiental. Ministério da Educação. Conselho Nacional de Educação. Disponível em: $<$ http://portal.mec.gov.br/dmdocuments/rcp002 12.pdf >. Acesso em 26 de junho de 2020.

CARNIATTO, I.; STEDING, A. Ambientalização e sustentabilidade nas universidades em debate. Rev. Eletrônica Mestr. Educ. Ambient., v. 32, n. 2, p. 299-318, 2015.

CARVALHO, J. R. M. DE et al. Percepção da Educação Ambiental : um estudo junto aos discentes de pós-graduação de uma IES no Estado da Paraíba. Revista Gest. Sust. Ambient., v. 4, n. 2, p. 234-253, 2016.

CAVALCANTI NETO, A. L. G. ; AMARAL, E. M. R. do. Ensino de ciências e Educação Ambiental no nível fundamental: análise de algumas estratégias didáticas. Ciência \& Educação, v. 17, n. 1, p. 129-144, 2011.

DIAS, G. F. Educação Ambiental: princípios e práticas. 9 ed. São Paulo. Gaia, 2004.

EDUARDO, J. R. de F. M. et al. Educação Ambiental e cotidiano: do paradigma moderno à ecologia dos saberes no âmbito de uma escola estadual. Revista Ciências \& Ideias, v. 9, n. 2, p. 94-114, 2018. 
FERNANDES, R.S. et al. Uso da percepção ambiental como instrumento de gestão em aplicações ligadas às áreas educacional, social e ambiental. Encontro Nacional de Pós-Graduação e Pesquissa em Ambiente e Sociedade, v. 2, n. 1, p. 1-15, 2004.

FONSECA, R. G.; BERNARDES, M. B. J. Formação e ação : reflexões sobre a Educação Ambiental no curso de graduação em geografia da Universidade de Coimbra - Portugal. Revista Brasileira de Educação Ambiental, v. 10, n. 4, p. 40-57, 2015.

FONSECA, J. R. B. da; MENDES, A. B. Educação Ambiental : uma compreensão analítico-discursiva. Revista Internacional de Direito Ambiental e Políticas Públicas, n. 5, p. 71-82, 2013.

FONSECA, S. M. A Educação Ambiental como disciplina. Revista Brasileira de Educação Ambiental, v. 11, n. 1, p. 305-314, 2016.

GELATI, G. R.; FAORO, D. Análise da percepção ambiental de educandos de uma escola municipal de Uruguaiana, RS. Revista Ciências \& Ideias, v. 8, n. 1, p. 23-45, 2017.

GOMES, S. G. S.; MOTA, J. B.; LEONARDO, E. da S. Reflexão sobre o perfil do aluno como determinante para a motivação e aprendizagem em curso de EAD.

Cad. Ed. Tec. Soc., Inhumas, v. 7, p. 355-363, 2014.

GUIMARÃES, M. Educação Ambiental crítica. Identidades da Educação Ambiental brasileira. Brasília: Ministério do Meio Ambiente, p. 25-34, 2004.

GUIMARÃES, M; LAYRARGUES, P. P. Identidades da Educação Ambiental brasileira. Ministério do Meio Ambiente. Diretoria de Educação Ambiental, p. 2534, 2004.

GUIMARÃES, M. Por uma Educação Ambiental crítica na sociedade atual. Revista Margens Interdisciplinar, v. 7, n. 9, p. 11-22, 2016.

INEP - Instituto Nacional de Estudos e Pesquisas Educacionais Anísio Teixeira. Censo da educação superior: 2018 - notas estatísticas. - Brasília. Instituto Nacional de Estudos e Pesquisas Educacionais Anísio Teixeira, 2019.

JACOBI, P. R. Educação Ambiental, cidadania e sustentabilidade. Cadernos de pesquisa, n. 118, p. 189-205, 2003.

LAYRARGUES, P.P.; LIMA, G.F.C. As macrotendências político-pedagógicas da Educação Ambiental brasileira. Ambiente \& Sociedade, v. 17, n. 1, p. 23-40, 2014.

LANDER, E. Ciências sociais: saberes coloniais e eurocêntricos. In: A colonialidade do saber: eurocentrismo e ciências sociais. Perspectivas latino-americanas. Buenos Aires: CLACSO, p. 21-53, 2005. 
LAYRARGUES, P. P. (Re)Conhecendo a Educação Ambiental brasileira. In: LAYRARGUES, P.P. (coord.). Identidades da Educação Ambiental brasileira. Ministério do Meio Ambiente. Diretoria de Educação Ambiental. Brasília: Ministério do Meio Ambiente, 2004. 156 p.

LOUREIRO, C. F. B. Premissas teóricas para uma Educação Ambiental transformadora. 2003.

LOUREIRO, C. F. B. Educação Ambiental transformadora. In: LAYRARGUES, P. P. Identidades da Educação Ambiental brasileira, Brasília, p. 65-84. 2004.

LOUREIRO, C. F. B.; LAYRARGUES, P. P. Ecologia política, justiça e Educação Ambiental crítica: perspectivas de aliança contra-hegemônica. Rev. Trab. Educ. Saúde v. 11, n. 1, p. 53-71. 2013

MATTHIESEN, A. Uso do coeficiente Alfa de Cronbach em avaliações por questionários. EMBRAPA, 2011.

MASSI, C. G. Práticas pedagógicas em Educação Ambiental - Política Nacional de Resíduos Sólidos - PNRS: uma abordagem crítica. In: ROSA-SILVA, LOPESLIMA, L. C. Anais... Diálogos com a Educação Ambiental: ações e desafios, 2016.

MEDEIROS, A. B. de; MENDONÇA, M. J. da S. L.; SOUSA, G. L. da; OLIVEIRA, I. P. A Importância da Educação Ambiental na escola nas séries iniciais. Revista Faculdade Montes Belos, v. 4, n. 1, set., 2011.

OLIVEIRA, L. H. de. Exemplo de cálculo de Ranking Médio para Likert. Notas de Aula. Metodologia Científica e Técnicas de Pesquisa em Administração. Mestrado em Adm. e Desenvolvimento Organizacional. PPGA CNEC/FACECA: Varginha, 2005.

PELIZZOLI, M. L. Correntes da ética ambiental. Petrópolis, RJ: Editora Vozes, 2003.

REIGOTA, M. Educação Ambiental: a emergência de um campo científico.

Perspectiva, v. 30, n. 2, p. 499-520, 2012.

RIBEIRO, M. T.; MALVESTIO, A. C. O ensino da temática ambiental nas instituições de ensino superior no Brasil. Revista Brasileira de Educação Ambiental, v.16, n.3, p.347-361, 2021.

ROSA, L. G., SILVA, M. M. P. 2002. Percepção ambiental de educandos de uma escola do ensino fundamental. Anais: 6o Simpósio Ítalo Brasileiro de Engenharia Sanitária e Ambiental, p. 1-5. 2002.

SEMESP. $\quad<$ https://www.semesp.org.br/noticias/semesp-levantamento-posgraducacao/>. Acesso 29 de junho de 2020.

SILVA JÚNIOR, S. D. da; COSTA, F. J. Mensuração e escalas de verificação: uma análise comparativa das escalas de Likert e Phrase Completion. Revista Brasileira de Pesquisas de Marketing, Opinião e Mídia. v. 15, p.1-16, 2014. 
SILVA, M. L. da. A Educação Ambiental no ensino superior brasileiro: do panorama nacional às concepções de alunos (as) de pedagogia na Amazônia. Rev. Eletrônica Mestr. Educ. Ambient., v. especial, 2013.

SILVA, M. M. P. DA et al. Quando Educação Ambiental faz a diferença, vidas são transformadas. Rev. Eletrônica Mestr. Educ. Ambient., v. 28, p. 388-402, 2012.

SORRENTINO, M.; BIOSOLI, S. Ambientalização das instituições de educação superior: a Educação Ambiental contribuindo para a construção de sociedades sustentáveis. In: RUSCHEINSKY et al. (orgs) Ambientalização nas instituições de educação superior no Brasil: caminhos trilhados, desafios e possibilidades. p. 39- 46, 2014.

SOUSA FILHO, J. M. de; COIMBRA, D. B.; MESQUITA, R. F. de; LUNA, R. A. Análise do comportamento ecológico de estudantes de administração. Revista Eletrônica de Administração (porto Alegre), v. 21, n. 2, p.300-319, ago. 2015.

SOUSA, T.; SANT'ANA JÚNIOR, H. A. de. Educação Ambiental crítica ou conservadora? elementos para uma reflexão crítica acerca do projeto ecoa. Ambiente \& Educação, v. 23, n. 1, p. 100-121, 2018.

STREINER, D. L. Being inconsistent about consistency: when coefficient alpha does and does't matter. Journal of Personality Assessment. v. 80, n. 3, p. 217222. 2003.

TORRES, J. R.; MAESTRELLI, S. R. P. Atributos de Educação Ambiental escolar no contexto educacional brasileiro: do movimento ambientalista internacional ao nacional. Rev. Eletrônica Mestr. Educ. Ambient., v. 28, p. 114-132, 2012.

TRISTÃO, M. A Educação Ambiental na formação de professores: redes de saberes. Annablume, 2004. 